all the others which have fallen under my care, clearly proves to my mind that it is perfectly safe and judicious to restore the bones in these cases at once to their natural position. Dame Nature is an excellent doctress, and must be kept in good humour, but every medical man knows full well that many cases are too mighty for her unaided efforts. To have applied splints and a bandage alone in this case would have been almost useless; to have left the bones bent almost to a right angle, and merely waited for the curative powers of nature, would have been preposterous.

The parents and friends of the child, I should think, would in that case have stared at me with astonishment, and in all probability I should ever afterwards have been subjected to well-merited reproach; even the bones themselves might have elboved and annoyed me in silent derision of mal praxis, whenever I came in contact with them.

DISLOCATION OR NOT OF THE WRIST-JOINT (?).

If, Sir, a single fact presented through the respectable medium of your widely-circulated $\mathbf{J}$ ournal will have any weight in settling the controversy lately carried on between your reporter and other gentlemen, I beg to offer one.

On the 3rd of September ult. my son was called to Mrs. Baggott, about sixty years of age, of Cannon-street, in this city, who had fallen from the top to the bottom of the stone cellar stairs of her own house; the whole weight of her heavy body having been received by her hands, with the exception of her forehead, which only received a slight contusion, and was well in a few days. Both bones of the right forearm were fractured at their lower third; and the radius of the left arm was broken at its lower extremity near the junction of the cartilage. The ligaments of both wrists were much strained and otherwise injured, but neither of the wrists were dislocated. The bones have knit, and the patient is fast recovering from the effects of the accident. I am, Sir, your obedient servant,

Bristol, Oct. 6, 1841.

James Prowse.

\section{ST. MARYLEBONE INFIRMARY.}

To the Editor of The LANCET.

SIR,-Having been one of the first pupils that entered to the medical practice of the Marylebone Infirmary since its recognition as an hospital by the A pothecaries' Company, I feel in duty bound, as well as from other reasons, to reply to the letter of your correspondent in last week's LANCET, signed "A former Pupil ;" in doin 8 so, I will not say anything about the writer of that letter having ever been a pupil of the infirmary, further than that $I$ am convinced there is no pupil that paid attention to the instruction given in that establishment, but will in aftertime, when in practice for himself, have reason to look back with satisfaction and pleasure on the hours he spent in it. As for my part, I would consider myself guilty of ingratitude, in return for the pains taken by the honorary medical officers in giving instruction, if $\mathbf{I}$ did not contradict the statement of your correspondent, as far as relates to the opportunities which offer, and the instruction given in the practice of physic and morbid anatomy, which, if not superior, are second to no other in London.

At the infirmary there are admitted only a limited number of pupils, which is a great advantage to those who enter, as all may hear the remarks made by the physicians;-so different from other hospitals, where, in the scramble to get a good place, three-fourths of what is said is lost even to those close to the bed.

The statement of your correspondent, that the pupils are hurried through the wards, is altogether incorrect, as sufficient time is given to take notes; and remarks, to a small extent, are made at the bedside of each patient by the physicians. When I entered as pupil to the medical practice in 1838 , the physicians then were Drs. Clendinning and Macreight; since that time a change has taken place in the medical staff, and the physicians who now give instruction are Drs. Clendinning and Mayo: of the former, I cannot speak too highly; of Dr. Mayo, who was but recently elected, I have not had the same opportunity of judging, as my attendance during the last six or eight months has not been very regular; but the few times I have been with him in the wards and deadhouse, he was at all times willing and ready to give me any instruction or information.

I cannot conclude this without stating, that from Mr. Phillips, who has delivered more than one course of lectures free to all the pupils, I have, in common with the other pupils, received on various occasions much instruction.

In what I have here stated, I am certain I shall be joined by all the pupils of the infirmary, for I question very much whether your correspondent was a pupil. It sometimes happens that men, though qualified by the seal of some corporate body to enter into practice, may require instruction, though the proper days of their pupilage has passed: such may be the case with your correspondent. Whoever he is, he should not make a charge, such as he has made, without giving' his name. To him I would say in the words of the poet-

" 'Tis not enough, taste, learning, judgment join, In all you state let truth and candour shine."

I am, Sir, yours obediently, WILLIAM O'ConNor, A. Pupil of the Infirmary for the last Three Years,

Wednesday, Oct. 13, 1841. 